\title{
Colony-stimulating Factors Regulate the Development of Multinucleated Osteoclasts from Recently Replicated Cells In Vitro
}

\author{
Joseph A. Lorenzo, Sandra L. Sousa, Judith M. Fonseca, Janet M. Hock, and Eugene S. Medlock \\ Departments of Medicine and Dentistry, Veterans Administration Medical Center, Newington, Connecticut 06111; and Departments of \\ Medicine, Restorative Dentistry, and Pathology, University of Connecticut Health Center, Farmington, Connecticut 06032
}

\begin{abstract}
Osteoclasts mediate the process of bone resorption. However, little is known about the mechanisms that regulate the formation of either osteoclasts or osteoclast precursors. In contrast, colonystimulating factors (CSFs) are well-known to regulate the formation of myeloid cells and their precursors. Because osteoclasts and myeloid cells may originate from a common stem cell, we examined the effects of two CSFs, granulocyte-macrophage CSF (GM-CSF) and interleukin 3 (IL-3), on bone resorption, osteoclast formation, and the incorporation of recently replicated nuclei into the osteoclasts of mouse bone cultures.

CSFs had little effect on the formation rate of osteoclasts or their resorptive activity but significantly decreased the percentage of recently replicated osteoclast progenitor cell nuclei present in the osteoclasts of bones treated with parathyroid hormone. GMCSF also increased the number of myeloid cells in the marrow space of the cultures and the percentage of these cells derived from recently replicated progenitors.

These results demonstrate that GM-CSF and IL-3 can regulate the development of osteoclasts from recently replicated precursor cells in cultured fetal mouse long bones. However, the mechanisms by which CSFs influence osteoclast formation are difficult to determine from these studies because markers for the osteoclast progenitor and precursor do not exist. These data also provide evidence that the differentiation of osteoclast progenitors is regulated by different factors at different points in their ontogeny.
\end{abstract}

\section{Introduction}

Osteoclasts are multinucleated giant cells that mediate the process of bone resorption (1-4). Osteoclasts do not replicate by cell division (5-7). Instead, they increase their size and number through the fusion and incorporation of a terminally differentiated cell, the osteoclast precursor. Osteoclast precursors are believed to originate from hematopoietic cells (8-11), and their replicating parent cell has been termed the osteoclast progenitor. Little is known about the mechanisms that regulate osteoclast progenitor cell replication or differentiation.

Many analogies exist between the osteoclast precursor cell and the macrophage (12-14), including the ability of macrophages to become multinucleated, destroy connective tissue, and release mineral from devitalized bone particles. However, recent experiments have demonstrated that macrophage giant cells do

Address reprint requests to Dr. Joseph Lorenzo, VA Medical Center, Building 5, 555 Willard Avenue, Newington, CT 06111. 1987.

Received for publication 22 August 1986 and in revised form 13 March

The Journal of Clinical Investigation, Inc.

Volume 80, July 1987, 160-164 not resorb large bone slices as true osteoclasts do, and they share few surface antigens with osteoclasts (15-17). The agents that regulate the replication and differentiation of myeloid (macrophage-granulocyte) progenitor cells (18-20) are well defined and have been termed colony-stimulating factors (CSFs). ${ }^{1}$ Four CSFs have been described: interleukin 3 (IL-3 or multi-CSF), granulocyte-macrophage colony stimulating factor (GM-CSF), colony-stimulating factor 1 (CSF-1, or M-CSF) and granulocyte colony-stimulating factor (G-CSF). IL-3 and GM-CSF stimulate the production of both macrophages and granulocytes, whereas CSF-1 and G-CSF enhance the production of only macrophages or granulocytes, respectively.

To determine if factors that regulate myeloid cell production also regulate osteoclast formation, we studied the ability of two CSFs, IL-3 and GM-CSF, to alter the formation and bone-resorbing activity of osteoclasts and the differentiation of replicating osteoclast progenitor cells into osteoclasts in cultured fetal mouse long bones.

\section{Methods}

Tissue culture. Radii and ulna from 18 day fetal mice were studied because they can be easily cultured in vitro and because they possess fully developed marrow cavities (21). We used two culture protocols for our experiments.

Protocol 1 was designed to examine the direct effects of CSFs on resorption. Bones were prelabeled with ${ }^{45} \mathrm{Ca}$ (Amersham Corp., Arlington Heights, IL) by injecting $100 \mu \mathrm{Ci}$ into the mothers $24 \mathrm{~h}$ before sacrifice. They were dissected free of surrounding muscle and fibrous tissue and their cartilaginous ends were removed using previously described techniques $(22,23)$. Bones were precultured in BGJ medium (Grand Island Biological Corp., Grand Island, NY) for $24 \mathrm{~h}$ immediately after dissection to remove readily exchangeable ${ }^{45} \mathrm{Ca}$. All media were supplemented with $5 \%$ (vol:vol) fetal bovine serum that had been heated to $57^{\circ} \mathrm{C}$ for $3 \mathrm{~h}$ and treated with dextran-coated charcoal to removed endogenous stimulators of resorption (5). After preculture bones were transferred to experimental medium for $72 \mathrm{~h}$. Cultures were terminated by placing the bones in 5\% TCA for $1 \mathrm{~h}$. Aliquots of medium and the TCA extract of the bones were counted for ${ }^{45} \mathrm{Ca}$ by liquid scintillation. Bone resorption was measured as the percentage of total ${ }^{45} \mathrm{Ca}$ (medium + bone) that was in the medium at the end of the experiments. Results were expressed as treated to control $(\mathrm{T} / \mathrm{C})$ ratios to allow data from multiple experiments to be compared.

Protocol 2 was designed to examine the effects of pretreating the cultures with CSFs. Bones prelabeled with ${ }^{45} \mathrm{Ca}$ were placed in medium that contained CSFs immediately after dissection and cultured for $48 \mathrm{~h}$ (pretreatment period). Bones were then transferred and cultured for various times (treatment period) in either control medium or medium that contained parathyroid hormone (PTH). PTH was added to the treatment medium to increase the rate that new osteoclasts formed. In these experiments resorption rates were measured only during the treatment period.

1. Abbreviations used in this paper: CSF, colony-stimulating factor, GMCSF, granulocyte macrophage colony-stimulating factor; IL-3, interleukin 3. 
Histology. Bones not labeled with ${ }^{45} \mathrm{Ca}$ were also cultured according to protocol 2 and examined histologically. At the conclusion of an experiment bones were fixed in $1.25 \%$ (vol:vol) glutaraldehyde in phosphate buffer and embedded in glycol-methacrylate. Three micron sections were stained with either hematoxylin-eosin or toluidine blue. Osteoclasts in midsections of the bones were identified by their proximity to bone, characteristic cytoplasm and multinucleation (1-5). Myeloid cells (macrophages, monocytes, polymorphonuclear granulocytes and eosinophils) in the marrow space of the cultures were identified by standard morphologic criteria at the light microscopic level (24). Bone sections were coded and random ordered before being read so that the investigator scoring them was blind to their treatment. In some experiments $\left[{ }^{3} \mathrm{H}\right]$ thymidine $(2 \mu \mathrm{Ci} / \mathrm{ml}, 400 \mathrm{nM}$, Amersham Corp.) was added to the medium during the pretreatment period to label replicating cells. Cultures were then either transferred to medium that contained $100 \mu \mathrm{M}$ cold thymidine without labeled thymidine (to block further incorporation of $\left[{ }^{3} \mathrm{H}\right]$ thymidine into DNA) or continued in medium that contained $\left[{ }^{3} \mathrm{H}\right]$ thymidine. Bone sections were processed for autoradiography using NT2-B dipping photographic emulsion (Eastman Kodak Corp., Rochester, NY) and developed for $48 \mathrm{~h}$. Nuclei in cells were defined as being labeled if they had 5 or more overlying grains.

Bone marrow agar cultures. $7.5 \times 10^{4}$ mouse bone marrow cells were cultured in semisolid agar treated with the indicated CSFs (22). Cultures were scored for colony ( $>50$ cells) generation on day 7-8 of culture.

Materials. Purified murine GM-CSF and IL-3 were purchased from Genzyme Corp., Cambridge, MA. They were isolated from the LBRM33 cell line according to the method of Prestidge et al. (25). Homogeneously purified murine IL-3 (a gift from Dr. James Ihle [26], NCIFrederick Cancer Research Facility, Frederick, MD) was also used in some experiments and was identical in its effects to commercial IL-3. Bovine parathyroid hormone 1-34 was purchased from Bachem Corp., Torrance, CA. All other reagents were from Sigma Chemical Co., St. Louis, MO.

Statistics. Significant differences between groups were analyzed by the Student's $t$ test except for experiments that examined the percentage of osteoclast nuclei that were $\left[{ }^{3} \mathrm{H}\right]$ thymidine labeled. These were analyzed by the chi-square test.

\section{Results}

Using culture protocol 1, bovine PTH, a stimulator of osteoclastic activity, increased resorption in these cultures after $72 \mathrm{~h}$ by about twofold (Table I). In contrast, GM-CSF (10 to $100 \mathrm{U} / \mathrm{ml}$ ) and IL-3 $(300 \mathrm{U} / \mathrm{ml})$ were either without effect or slightly inhibitory. However, both CSFs enhanced myeloid cell colony formation in semisolid agar cultures of mouse bone marrow cells (Table II). All experiments described in Tables I and II have been repeated at least once with identical results.

We next examined the effects of pretreating the cultures with CSFs (protocol 2). In bones pretreated in control medium, a subsequent 48-h treatment with PTH increased both the rate of resorption and the number of osteoclasts per bone by about twofold (Table III). PTH also tended to increase the number of nuclei per osteoclast. However, this effect was small and not always significant. Pretreatment of the cultures with CSFs did not alter ${ }^{45} \mathrm{Ca}$ release, osteoclasts per bone section or nuclei per osteoclast in bones transferred to either control or PTH containing medium.

Pretreatment with GM-CSF had no effect on the number of osteoclasts in bones that were examined at the end of the pretreatment period $(5.0 \pm 0.6$ in the control, $4.9 \pm 0.4$ in the GMCSF group). Similarly, GM-CSF pretreatment did not alter the percentage of osteoclast nuclei that were labeled in bones that had $\left[{ }^{3} \mathrm{H}\right]$ thymidine added to their pretreatment medium $(\mathrm{t}=0$ in Fig. $1 A$ ). However, the percentage of labeled osteoclast nuclei in either group after the pretreatment period was small $(<2 \%)$.
Table I. Effects of GM-CSF and IL-3 on Bone Resorption in Fetal Mouse Long Bone Cultures

\begin{tabular}{lrl}
\hline Group & & $\begin{array}{l}\text { is Ca percent release } \\
\text { T/C ratio }\end{array}$ \\
\hline Control & & $1.00 \pm 0.05$ \\
PTH & $100 \mathrm{ng} / \mathrm{ml}$ & $2.23 \pm 0.19^{*}$ \\
GM-CSF & $10 \mathrm{U} / \mathrm{ml}$ & $0.97 \pm 0.02$ \\
GM-CSF & $30 \mathrm{U} / \mathrm{ml}$ & $0.98 \pm 0.05$ \\
GM-CSF & $100 \mathrm{U} / \mathrm{ml}$ & $0.92 \pm 0.02$ \\
IL-3 & $300 \mathrm{U} / \mathrm{ml}$ & $0.88 \pm 0.01^{\ddagger}$ \\
\hline
\end{tabular}

Values are mean \pm SEM for 4-6 bones per group. Results are expressed as treated to control (T/C) ratios to allow data from two experiments to be compared. Experiment 1 was composed of a control group and all the GM-CSF groups. Experiment 2 was composed of a control group, the PTH group, and the IL-3 group. Control resorption rates were $11.6 \pm 0.6$ and $26.7 \pm 1.2$ for the two experiments, respectively. Results are expressed in one column to save space since the SEM for both control groups was $5 \%$.

* Significantly different from control $P<0.01,{ }^{\ddagger} P<0.05$.

In contrast, GM-CSF pretreatment increased both the number of myeloid cells in the marrow space of these bones and the percentage of myeloid cells that were $\left[{ }^{3} \mathrm{H}\right]$ thymidine labeled (Table IV). A repeat of the experiments described in Tables III and IV yielded identical results.

In bones that were pretreated in control medium that contained $\left[{ }^{3} \mathrm{H}\right]$ thymidine and then transferred to medium that contained high concentrations of cold thymidine, treatment with PTH for $\mathbf{4 8 ~ h}$ markedly increased the percentage of labeled osteoclast nuclei compared to bones that were maintained in control medium ( $t=24$ and 48 in Fig. $1 A$ ).

There was no significant effect on the percentage of labeled osteoclast nuclei of pretreating bones with GM-CSF if bones were subsequently treated in control medium for up to $48 \mathrm{~h}$ or with PTH for $24 \mathrm{~h}$. In contrast, in bones that were treated with PTH for $48 \mathrm{~h}$, GM-CSF pretreatment decreased the percentage of labeled osteoclast nuclei by about half compared to bones pretreated in control medium ( $t=48$ in Fig. $1 A)$.

The inhibitory effects that GM-CSF pretreatment had on the labeling of osteoclast nuclei in PTH treated bones in Fig. 1 $A$ was not altered when $\left[{ }^{3} \mathrm{H}\right]$ thymidine without cold thymidine was present in both the pretreatment and treatment medium (Fig. $1 B$ ). Hence, this effect did not appear to result from the rapid turnover and dilution of labeled thymidine during the treatment period (when cold thymidine was in the medium).

Pretreatment of bone with IL-3 for $48 \mathrm{~h}$ had effects that were similar to those of GM-CSF (Fig. $1 C$ ). In bones transferred to

Table II. Effects of GM-CSF and IL-3 on the Number of Myeloid Colonies That Formed in Agar Cultures of Murine Bone Marrow Cells

\begin{tabular}{lll}
\hline Group & & $\begin{array}{l}\text { Myeloid colonies } \\
\text { per } 10^{5} \text { cultured cells }\end{array}$ \\
\hline Control & & None \\
GM-CSF & $100 \mathrm{U} / \mathrm{ml}$ & $121.5 \pm 10.9^{*}$ \\
IL-3 & $100 \mathrm{U} / \mathrm{ml}$ & $112.2 \pm 10.5^{*}$ \\
\hline
\end{tabular}

Values are mean \pm SEM three cultures per group.

* Significantly different from control $P<0.01$. 
Table III. Effects of a 48-H Pretreatment with GM-CSF

or IL-3 on Resorption, the Number of Osteoclasts

and the Number of Nuclei per Osteoclast in Fetal

Mouse Long Bone Cultures Treated with PTH

\begin{tabular}{llcl}
\cline { 1 - 2 } Group & & & \\
\cline { 1 - 2 } Pretreatment $\rightarrow$ treatment & $\begin{array}{l}48 \mathrm{~h}^{45} \mathrm{Ca} \text { release } \\
\mathrm{T} / \mathrm{C} \text { ratio }\end{array}$ & $\begin{array}{l}\text { Osteoclasts } \\
\text { per midsection }\end{array}$ & $\begin{array}{l}\text { Nuclei } \\
\text { per osteoclast }\end{array}$ \\
\cline { 1 - 3 } Experiment 1 & & & \\
$\quad$ Control $\rightarrow$ Control & $1.00 \pm 0.01$ & $4.5 \pm 0.6$ & $2.8 \pm 0.1$ \\
Control $\rightarrow$ PTH & $1.83 \pm 0.14^{*}$ & $10.3 \pm 1.5^{*}$ & $3.2 \pm 0.1^{\ddagger}$ \\
GM-CSF $\rightarrow$ Control & $0.97 \pm 0.02$ & $4.2 \pm 1.5$ & $2.9 \pm 0.1$ \\
GM-CSF $\rightarrow$ PTH & $2.08 \pm 0.07^{*}$ & $8.8 \pm 0.7^{*}$ & $3.1 \pm 0.1$ \\
Experiment 2 & & & \\
Control $\rightarrow$ Control & $1.00 \pm 0.02$ & $6.2 \pm 1.4$ & $2.8 \pm 0.1$ \\
Control $\rightarrow$ PTH & $1.76 \pm 0.08^{*}$ & $11.3 \pm 1.4^{*}$ & $2.9 \pm 0.1$ \\
IL-3 $\rightarrow$ Control & $0.99 \pm 0.03$ & $5.5 \pm 1.0$ & $2.7 \pm 0.1$ \\
IL-3 $\rightarrow$ PTH & $1.63 \pm 0.09^{*}$ & $9.8 \pm 1.0^{*}$ & $2.9 \pm 0.1$ \\
& & & \\
\hline
\end{tabular}

Bones were pretreated as indicated for $48 \mathrm{~h}$ immediately after dissection and then transferred to additional treatments for $48 \mathrm{~h}$. Resorption was measured during the second culture period only. PTH $100 \mathrm{ng} / \mathrm{ml}$, GM-CSF $100 \mathrm{U} / \mathrm{ml}$ and IL-3 $300 \mathrm{U} / \mathrm{ml}$. Values are mean \pm SEM for 4-6 bones per group. Control resorption rates were $11.7 \pm 0.4$ and

$17.4 \pm 0.3$ for experiments 1 and 2 , respectively.

* Significantly different from control $P<0.01,{ }^{\ddagger} P<0.05$.

control medium, the percentage of labeled osteoclast nuclei was not different from that of bones pretreated in control. However, in bones that were cultured with PTH for $48 \mathrm{~h}$, pretreatment with IL-3 decreased the percentage of labeled osteoclast nuclei by about half.

The inhibitory effect that pretreatment with GM-CSF or IL3 had on the percentage of osteoclast nuclei that were $\left[{ }^{3} \mathrm{H}\right]$ thymidine labeled in PTH treated bones occurred only in bones that were pretreated with $100 \mathrm{U} / \mathrm{ml}$ or greater concentrations of GM-CSF or IL-3 (Tables V and VI).

\section{Discussion}

The effects that PTH had on resorption in $18 \mathrm{~d}$ fetal mouse long bone cultures appeared to be mediated by osteoclasts since increases in resorption directly correlated with increases in osteoclast number. PTH rapidly (within $48 \mathrm{~h}$ ) increased the number of osteoclasts in the bones compared to the life span of an osteoclast (estimated to be as long as $6 \mathrm{wk}$ in vivo [27]) and it increased the percentage of recently replicated nuclei in osteoclasts. Hence, the effect of PTH on osteoclast number appeared to result from an increase in the rate that osteoclast precursor

Table IV. Effects of GM-CSF on the Number of Myeloid Cells and the Percentage of Myeloid Cells That Derived from Recently Replicated Progenitors in Cultured Fetal Mouse Long Bones

\begin{tabular}{|c|c|c|c|}
\hline Group & & $\begin{array}{l}\text { Myeloid cells } \\
\text { per midsection of bone }\end{array}$ & $\begin{array}{l}\text { Percent labeled } \\
\text { myeloid cells per bone }\end{array}$ \\
\hline Control & & $37.8 \pm 6.3$ & $11 \pm 2$ \\
\hline GM-CSF & $100 \mathrm{U} / \mathrm{ml}$ & $69.0 \pm 8.5^{*}$ & $39 \pm 5^{*}$ \\
\hline
\end{tabular}

Bones were cultured for $48 \mathrm{~h}$ with $\left[{ }^{3} \mathrm{H}\right]$ thymidine $2 \mu \mathrm{CI} / \mathrm{ml}$. Values are mean \pm SEM for 8 to 10 bone sections per group.

* Significant effect of GM-CSF $P<0.01$. cells were incorporated into new osteoclasts and not from a decrease in the rate that osteoclasts were lost.

We have previously determined that inhibitors of DNA synthesis do not block the ability of PTH to stimulate new osteoclast formation or bone resorption in fetal rat long bone cultures (5). These data demonstrate that the effect of PTH on the number of osteoclasts in bone cultures occurs through recruitment of available precursor cells into new osteoclasts without regard to whether the osteoclast precursors that are recruited are derived from recently replicated cells. Based on these findings, it appears that in the present experiments PTH increased the percentage of $\left[{ }^{3} \mathrm{H}\right]$ thymidine labeled nuclei in osteoclasts by recruiting osteoclast precursors that were derived from progenitors that had a relatively high rate of replication during the pretreatment period (when $\left[{ }^{3} \mathrm{H}\right]$ thymidine was present in the medium). In contrast, in bones cultured in control medium during the treatment period the percentage of osteoclast nuclei that were labeled was low. This result implies that in the absence of PTH the rate of incorporation of new nuclei into osteoclasts is slower. It is unlikely that PTH increased the percentage of labeled osteoclast nuclei in the cultures by altering the rate that osteoclast progenitor cells replicated because this effect occurred in bones that were labeled with $\left[{ }^{3} \mathrm{H}\right]$ thymidine during the pretreatment period (before PTH was added). In addition, in these experiments, high concentrations of cold thymidine were added with PTH to the treatment medium to block further incorporation of the label into cells.

GM-CSF and IL-3 had little if any effect on osteoclast number or bone resorption rates and they did not alter the percentage of labeled nuclei in the osteoclasts of bones subsequently transferred to control conditions (where few new osteoclasts formed). However, pretreatment of bones with GM-CSF and IL-3, markedly inhibited the percentage of recently replicated nuclei in the osteoclasts of bones that were subsequently treated with PTH for $48 \mathrm{~h}$. Since PTH stimulated new osteoclast formation in these cultures by increasing the recruitment of osteoclast precursor cells into osteoclasts, GM-CSF and IL-3 could only have produced their effects on the nuclear labeling of osteoclast in PTH treated bones if they decreased the percentage of available osteoclast precursor cells that were derived from recently replicated progenitors.

The current experiments can not determine the mechanism by which CSFs decreased the percentage of available osteoclast precursor cells that were derived from recently replicated progenitors because there are no markers for the osteoclast progenitor or precursor cell that would allow us to follow their progression into osteoclasts. However, there are a number of potential explanations for our results. It is possible that CSFs stimulated progenitor/stem cell replication and simultaneously retarded the differentiation of osteoclast progenitors into precursors. This hypothesis would predict that after longer treatment times than we are able to perform in our bones cultures the percentage of labeled nuclei in osteoclasts would be increased in bones that were pretreated in CSFs. The recent findings of MacDonald et al. that CSFs increased the formation of osteoclastlike cells in long-term ( $21 \mathrm{~d}$ ) baboon bone marrow cultures that are treated with $1,25(\mathrm{OH})_{2}$ vitamin $\mathrm{D}(28)$ support this hypothesis.

It is also possible that CSFs directed the differentiation of a common osteoclast-myeloid progenitor cell away from the osteoclast precursor cell pathway and towards that of myeloid cells. This hypothesis is supported by the ability of GM-CSF to increase both the number of myeloid cells in these cultures and the percentage of myeloid cells that were derived from recently repli- 

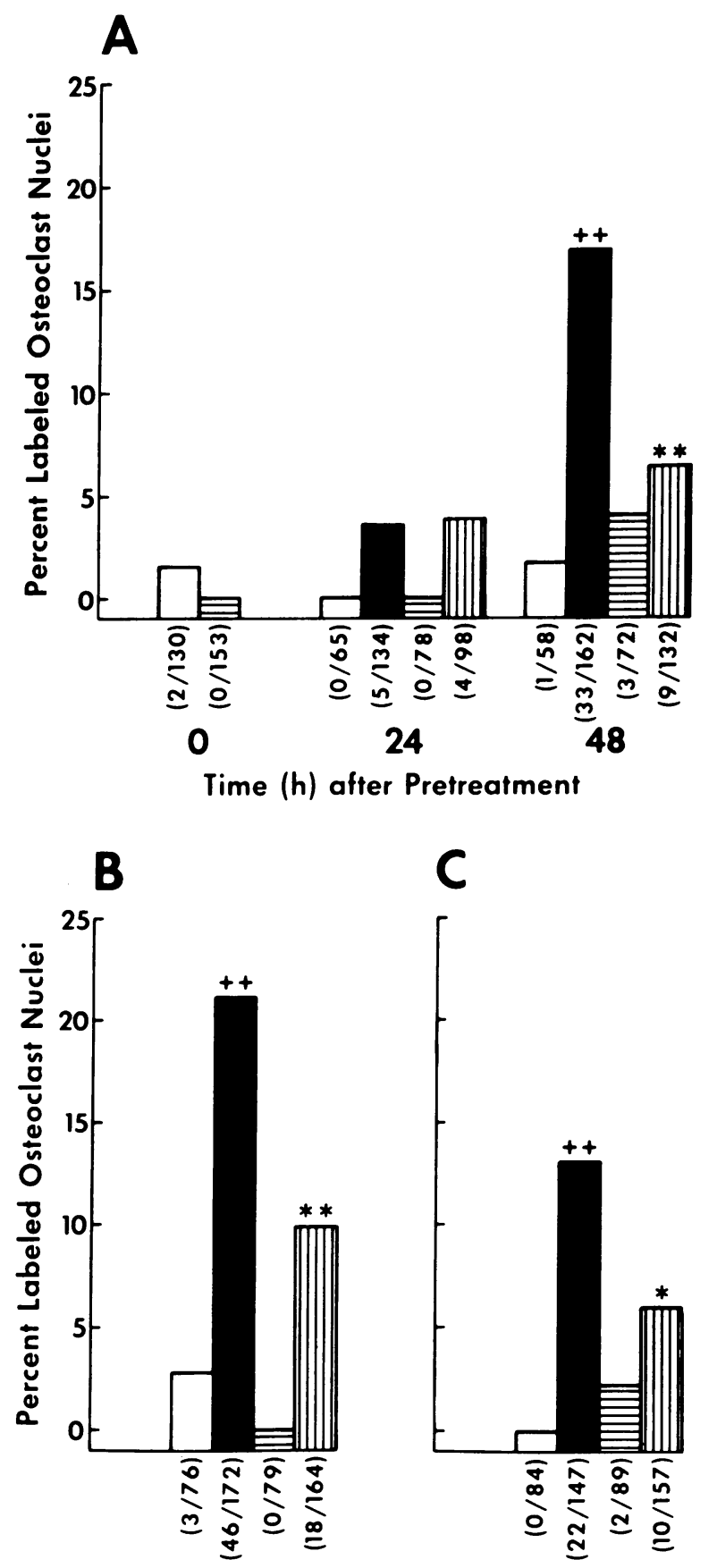

Figure 1. (A) Effects of a 48-h pretreatment with GM-CSF on the percentage of nuclei in osteoclasts that derived from cells that replicated during the pretreatment period. Pretreatment media contained $\left[{ }^{3} \mathrm{H}\right]$ thymidine $(2 \mu \mathrm{Ci} / \mathrm{ml}, 400 \mathrm{nM})$. Treatment media contained 100 $\mu \mathrm{M}$ cold thymidine without labeled thymidine. Clear bars: control pretreatment $\rightarrow$ control treatment. Solid bars: control pretreatment $\rightarrow$ PTH $(100 \mathrm{ng} / \mathrm{ml})$ treatment. Horizontal hatched bars: GM-CSF pretreatment $(100 \mathrm{U} / \mathrm{ml}) \rightarrow$ control treatment. Vertical hatched bars: GM-CSF pretreatment $\rightarrow$ PTH treatment. Experiments were terminated directly after the pretreatment period, after $24 \mathrm{~h}$ of treatment and after $48 \mathrm{~h}$ of treatment. Numbers in parentheses are the total number of labeled/unlabeled osteoclast nuclei in each group. ${ }^{++}$Signifcant effect of PTH $P<0.01$. **Significant effect of GM-CSF pretreatment $P<0.01$. Differences between groups were analyzed by the chisquare test. $(B)$ Effects of maintaining $\left[{ }^{3} \mathrm{H}\right]$ thymidine in both the pretreatment $(48 \mathrm{~h})$ and treatment media $(48 \mathrm{~h})$. Symbols are the same as in $(A)$. $(C)$ Effect of IL-3 pretreatment $(48 \mathrm{~h})$ and indicated treatment $(48 \mathrm{~h})$. Bones were treated with $\left[{ }^{3} \mathrm{H}\right]$ thymidine as in $(A)$. Clear bars:
Table V. Dose-response Effects of GM-CSF on the Percentage of Osteoclast Nuclei That Were $\left[{ }^{3} \mathrm{H}\right]$ Thymidine Labeled in Fetal Mouse Long Bone Cultures

\begin{tabular}{llll}
\hline Group & $\begin{array}{l}\text { No. } \\
\text { labeled } \\
\text { osteoclast } \\
\text { nuclei }\end{array}$ & $\begin{array}{l}\text { No. } \\
\text { unlabeled } \\
\text { osteoclast } \\
\text { nuclei }\end{array}$ & $\begin{array}{l}\text { Labeled } \\
\text { osteoclast } \\
\text { nuclei }\end{array}$ \\
\hline Pretreatment $\rightarrow$ treatment & & & $\%$ \\
\hline & 1 & 63 & 1.6 \\
Control $\rightarrow$ Control & 2 & 56 & 3.4 \\
GM-CSF $(100 \mathrm{U} / \mathrm{ml}) \rightarrow$ Control & 2 & 57 & 3.4 \\
GM-CSF $(30 \mathrm{U} / \mathrm{ml}) \rightarrow$ Control & 2 & 34 & 2.9 \\
GM-CSF $(10 \mathrm{U} / \mathrm{ml}) \rightarrow$ Control & 1 & & \\
Control $\rightarrow$ PTH $(100 \mathrm{ng} / \mathrm{ml})$ & 23 & 96 & $19.3^{*}$ \\
GM-CSF $(100 \mathrm{U} / \mathrm{ml}) \rightarrow$ PTH & 5 & 103 & $4.6^{\ddagger}$ \\
GM-CSF $(30 \mathrm{U} / \mathrm{ml}) \rightarrow$ PTH & 18 & 108 & 14.3 \\
GM-CSF $(10 \mathrm{U} / \mathrm{ml}) \rightarrow$ PTH & 15 & 104 & 12.6 \\
\hline
\end{tabular}

Bones were pretreated as indicated for $48 \mathrm{~h}$ immediately after dissection and then transferred to additional treatments for $48 \mathrm{~h}$.

* Significant effect of PTH $P<0.01$.

* Significant effect of GM-CSF $P<0.01$.

Differences between groups were analyzed by the chi-square test.

cated progenitors. The failure of CSFs to decrease the number or size of the osteoclasts in the cultures is not inconsistent with this hypothesis since we have previously found that large numbers of preformed osteoclasts precursor cells (relative to the numbers of new osteoclasts that form) are present in cultured bones at the time of their dissection (5). However, this hypothesis is inconsistent with the known ability of IL-3 to stimulate the formation of a wide variety of other hematopoietic cell types in vitro (18-20) and if true would imply that factors other than CSFs stimulate the differentiation of the osteoclast precursor from its stem cell.

Both of these first two hypotheses are consistent with the recent findings of Scheven et al. (11) that osteoclast progenitor cells are derived from a population of myeloid stem cells that require IL-3 to be maintained in culture. However, because Scheven et al. did not examine the effects that CSFs had on the rate that osteoclasts formed from marrow cells in their bone cultures, we are unable to say what, if any effects, CSFs have on the differentiation of osteoclasts from progenitors in their cultures.

Our results could also be explained if the predominant effect of CSFs on mouse bone cultures was to increase the rate that osteoclast progenitors that were present in the cultures at the time of their dissection differentiated into osteoclast precursors in the absence of cell replication. This response to CSFs would have decreased the percentage of labeled osteoclast precursors that were available for incorporation into osteoclasts by increasing the number of unlabeled osteoclast precursor cells. It is unlikely that nonspecific toxicity of CSFs towards osteoclast progenitors is an explanation for the effects we observed since GMCSF increased the formation of myeloid cells in these cultures.

control pretreatment $\rightarrow$ control treatment. Solid bars: control pretreatment $\rightarrow$ PTH $(100 \mathrm{ng} / \mathrm{ml})$ treatment. Horizontal hatched bars: IL-3 $(300 \mathrm{U} / \mathrm{ml})$ pretreatment $\rightarrow$ control treatment. Vertical hatched bars: IL-3 pretreatment $\rightarrow$ PTH treatment. ${ }^{++}$Significant effect of PTH $P<0.01$. *Significant effect of IL-3 pretreatment $P<0.05$. Differences between groups were analyzed by the chi-square test. 
Table VI. Dose-response Effects of IL-3 on the Percentage of Osteoclast Nuclei That Were $\left[{ }^{3} H\right]$ Thymidine Labeled in Fetal Mouse Long Bone Cultures

\begin{tabular}{lccc}
\hline Group & $\begin{array}{l}\text { No. } \\
\text { labeled } \\
\text { osteoclast } \\
\text { nuclei }\end{array}$ & $\begin{array}{l}\text { No. } \\
\text { unlabeled } \\
\text { osteoclast } \\
\text { nuclei }\end{array}$ & $\begin{array}{l}\text { Labeled } \\
\text { osteoclast } \\
\text { nuclei }\end{array}$ \\
\hline Pretreatment $\rightarrow$ treatment & & & $\%$ \\
\hline & 0 & 39 & 0 \\
Control $\rightarrow$ Control & 2 & 63 & 3.1 \\
IL-3 $(300 \mathrm{U} / \mathrm{ml}) \rightarrow$ Control & 0 & 58 & 0 \\
IL-3 $(100 \mathrm{U} / \mathrm{ml}) \rightarrow$ Control & 0 & 82 & 2.4 \\
IL-3 $(30 \mathrm{U} / \mathrm{ml}) \rightarrow$ Control & 2 & 154 & 11.5 \\
Control $\rightarrow$ PTH $(100 \mathrm{ng} / \mathrm{ml})$ & 20 & 106 & $3.6^{*}$ \\
IL-3 $(300 \mathrm{U} / \mathrm{ml}) \rightarrow$ PTH & 4 & 128 & $3.8^{*}$ \\
IL-3 $(100 \mathrm{U} / \mathrm{ml}) \rightarrow$ PTH & 5 & 148 & 9.2 \\
IL-3 $(30 \mathrm{U} / \mathrm{ml}) \rightarrow$ PTH & 15 & & \\
\hline
\end{tabular}

Bones were pretreated as indicated for $48 \mathrm{~h}$ immediately after dissection and then transferred to additional treatments for $\mathbf{4 8 ~ h}$.

* Significant effect of IL-3 $P<0.05$.

Differences between groups were analyzed by the chi-square test.

Our results also suggest that the processes of osteoclast formation and bone resorption are regulated at two points. CSFs appear to influence the number of osteoclast precursors that are available for incorporation into osteoclasts but have little direct effect on osteoclast formation. In contrast, PTH appears to increase the number of osteoclasts in bone by increasing the recruitment of available precursors into new osteoclasts. In addition, PTH is also capable of activating bone resorbing activity in existing osteoclasts by an indirect mechanism (29).

\section{Acknowledgments}

Supported by National Institutes of Health grants AR-31263 and DE07272. Dr. Lorenzo and Dr. Hock are recipients of Research Associate Career Development Awards from the Veterans Administration.

\section{References}

1. Gothlin, G., and J. L. E. Ericsson. 1976. The osteoclast: review of ultrastructure, origin and structure function relationship. Clin. Orthop. Relat. Res. 120:201-231.

2. Hall, B. K. 1975. The origin and fate of osteoclasts. Anat. Rec. 183:1-11.

3. Hanoaka, H. 1978. The origin of the osteoclast. Clin. Orthop. Relat. Res. 145:252-263.

4. Loutit, J. F., and N. W. Nisbet. 1982. The origin of osteoclasts. Immunobiology. 161:193-203.

5. Lorenzo, J. A., L. G. Raisz, and J. M. Hock. 1983. DNA synthesis is not necessary for osteoclastic responses to parathyroid hormone in cultured fetal rat long bones. J. Clin. Invest. 72:1924-1929.

6. Krieger, N. S., R. S. Feldman, and A. H. Tashjian, Jr. 1982. Parathyroid hormone and calcitonin interactions in bone: irradiation-induced inhibition of escape in vitro. Calcif. Tissue Res. 2:197-203.

7. Scheven, B. A. A., E. H. Burger, E. W. M. Kawilarang-De Haas, A. M. Wassenaar, and P. J. Nijweide. 1985. Effects of ionizing irradiation on formation and resorbing activity of osteoclasts in vitro. Lab. Invest. 53:72-79.

8. Walker, D. G. 1975. Bone resorption restored in osteopetrotic mice by transplants of normal bone marrow and spleen cells. Science (Wash. DC). 190:784-785.

9. Kahn, A. J., and D. J. Simmons. 1975. Investigation of cell lineage in bone using chimaera of chicks and quail embryonic tissue. Nature (Lond.). 258:325-327.

10. Jotereau, F. U., and N. M. LeDouarin. 1978. The development relationship between osteocytes and osteoclasts. A study using the quailchick nuclear marker in endochondral ossification. Dev. Biol. 63:253265.

11. Scheven, B. A. A., J. W. M. Visser, P. J. Nijweide. 1986. In vitro osteoclast generation from different bone marrow fractions, including a highly enriched haematopoietic stem cell population. Nature (Lond.). 321:79-81.

12. Mundy, G. R., A. J. Altman, M. D. Gondek, and J. G. Bandelin. 1977. Direct resorption of bone by human monocytes. Science (Wash. DC). 196:1109-1111.

13. Kahn, A. J., C. C. Stewart, and S. L. Teitelbaum. 1978. Contactmediated bone resorption by human monocytes in vitro. Science (Wash. DC). 199:988-989.

14. Teitelbaum, S. L., C. C. Steward, and A. J. Kahn. 1979. Rodent peritoneal macrophages as bone resorbing cells. Calcif. Tissue Int. 27: 255-261.

15. Chambers, T. J., and M. A. Horton. 1984. Failure of cells of the mononuclear phagocytic series to resorb bone. Calcif. Tissue Int. 36: 556.

16. Horton, M. A., E. F. Rimmer, D. Lewis, J. A. S. Pringle, K. Fuller, and T. J. Chambers. 1984. Cell surface characterization of the human osteoclast: phenotypic relationship to other bone marrow-derived cell types. J. Pathol. 144:281-294.

17. Chambers, J. J., and M. A. Horton. 1984. Osteoclasts: putative, surrogate and authentic. J. Pathol. 144:295-296.

18. Pluznik, D. H., R. E. Cunningham, and P. D. Noguchi. 1984. Colony-stimulating factor (CSF) controls proliferation of CSF-dependent cells by acting during the $\mathrm{G}_{1}$ phase of the cell cycle. Proc. Natl. Acad. Sci. USA. 81:7451-7455.

19. Metcalf, D. 1985. The granulocyte-macrophage colony-stimulating factors. Science (Wash. DC). 229:16-22.

20. Dexter, T. M. 1984. Blood cell development. The message in the medium. Nature (Lond.). 309:746-747.

21. Schwartz, Z., A. Ornoy, and W. A. Soskolne. 1985. An in vitro assay of bone development using fetal long bones of mice: morphological studies. Acta Anat. 124:197-205.

22. Raisz, L. G. 1965. Bone resorption in tissue culture factors influencing the response to parathyroid hormone. J. Clin. Invest. 44:103116.

23. Stern, P. H., and L. G. Raisz. 1979. Organ culture of bone. In Skeletal Research. An Experimental Approach. D. J. Simmons and A. S. Kunin, editors. Academic Press, Inc., New York. 21-59.

24. Metcalf, D. 1977. Hemopoietic Colonies: In Vitro Cloning of Normal and Leukemic Cells. Springer-Verlag, Berlin.

25. Prestidge, R. L., J. D. Watson, D. L. Urdal, D. Mochizuki, P. Conlon, and S. Gillis. 1984. Biochemical comparison of murine colonystimulating factors secreted by a $\mathrm{T}$ cell lymphoma and a myelomonocytic leukemia. J. Immunol. 133:293-298.

26. Ihle, J. N., J. Keller, L. Henderson, F. Klein, and E. W. Palaszynski. 1982. Procedures for the purification of interleukin 3 to homogeneity. J. Immunol. 129:2431-2436.

27. Marks, S. C., Jr., and M. F. Seifert. 1985. The lifespan of osteoclasts: experimental studies using the giant granule cytoplasmic marker characteristic of beige mice. Bone (N. Y.). 6:451-455.

28. MacDonald, B. R., G. R. Mundy, S. Clark, E. A. Wang, T. J. Keuhl, E. R. Stanley, and G. D. Roodman. 1986. Effects of human recombinant CSF-GM and highly purified CSF-1 on the formation of multinucleated cells with osteoclast characteristics in long-term bone marrow cultures. J. Bone Miner. Res. 1:227-233.

29. McSheehy, P. M. J., and T. J. Chambers. 1986. Osteoblastic cells mediate osteoclastic responsiveness to parathyroid hormone. Endocrinology. 118:824-828. 